\title{
Long-term outcomes of the Ross procedure in adults
}

\author{
William H. Ryan, John J. Squiers, Katherine B. Harrington, Tammy Goodenow, Courtney Rawitscher, \\ Justin M. Schaffer, J. Michael DiMaio, William T. Brinkman \\ Baylor Scott \& White The Heart Hospital, Plano, TX, USA \\ Correspondence to: John J. Squiers, MD. Baylor Scott \& White The Heart Hospital, 1100 Allied Drive, Plano, TX 75093, USA. \\ Email: john.squiers@bswhealth.org.
}

\begin{abstract}
Background: The optimal aortic valve replacement for young and middle-aged adults remains elusive. Although several high-volume international centers and surgeons have demonstrated excellent long-term results with the pulmonary autograft (Ross procedure) in adult patients, current guidelines from the United States do not favor this technique. We evaluated long-term clinical and echocardiographic outcomes of adult patients undergoing the Ross procedure at our center.

Methods: A retrospective review of 225 consecutive adult patients undergoing the Ross procedure was completed. Kaplan-Meier analysis was performed to evaluate overall survival, which was then compared to an age- and sex-matched general population with the log-rank test. Accounting for death as a competing hazard, the cumulative incidence of reintervention and autograft or homograft dysfunction were estimated over the long-term.

Results: Mean age was $42 \pm 11$ years, and $62(28 \%)$ patients were at least 50 years old. A bicuspid aortic valve was present in 179 (80\%) patients. The most common indications for surgery were aortic insufficiency $(n=94,43 \%)$, aortic stenosis $(n=81,36 \%)$, and mixed etiology $(n=46,21 \%)$. In-hospital mortality was $0.9 \%$. Overall survival (with 95\% confidence intervals) at 1-, 10- and 20-year was 97.8\% (95.9-99.7\%), 94.2\% (91.0-97.4\%), and $81.3 \%$ (74.8-88.3\%), respectively. Overall survival approximated that of the general population (log-rank $\mathrm{P}=0.32$ ). The cumulative incidence (with $95 \%$ confidence intervals) of any autograft or homograft reintervention at 10-, 15-, and 20-year was 16\% (12-20\%), 28\% (21-35\%), and 45\% (36-54\%), respectively.

Conclusions: The Ross procedure restores a normal life expectancy to young and middle-aged adults with severe aortic valve disease. The need for reintervention increases steadily during the second decade after the Ross procedure, but less than half of patients require any reintervention for up to 20-year.
\end{abstract}

Keywords: Ross procedure; pulmonary autograft; long-term outcomes

Submitted Apr 23, 2021. Accepted for publication May 16, 2021.

doi: 10.21037/acs-2021-rp-fs-28

View this article at: https://dx.doi.org/10.21037/acs-2021-rp-fs-28

\section{Introduction}

Management of young- and middle-aged adults with aortic valve disease remains challenging. Commonly used options for surgical aortic valve replacement (SAVR) have inherent drawbacks: bioprosthetic valves are subject to structural valve deterioration requiring reintervention, and mechanical valves require life-long anticoagulation. Furthermore, SAVR has been associated with a reduction in life-expectancy of up to nearly $30 \%$ as compared to the general population, whether a bioprosthetic or mechanical valve is implanted, and loss of life-years is greater in younger patients (1). Pulmonary autograft replacement, first described by Ross in 1967 (2), offers an alternative therapy for younger adults that may overcome several limitations of SAVR in this population (3-6).

High-volume centers and surgeons have reported excellent short-, mid-, and long-term outcomes following the Ross procedure in adults, with recent reports published 
from Australia (7), Austria (8), Germany (9), and Canada (10-12). Two recent multi-center, international registry reports have confirmed and extended these findings $(13,14)$. However, the Ross procedure accounts for less than $0.1 \%$ of all aortic valve replacements performed in the United States (15). Citing concerns regarding increased perioperative risk of morbidity and mortality due to operative complexity as well as fear of autograft dilation and subsequent regurgitation that may require reintervention over time, the most recent American Heart Association/American College of Cardiology guidelines give only class IIb support for the Ross procedure when performed by experienced Ross surgeons (16), while the Society of Thoracic Surgeons (STS) guidelines actually oppose the Ross procedure in middleaged adults, in any patient with bicuspid aortic valve, and in patients with aortic regurgitation or aortic dilation (17).

Despite a dearth of enthusiasm in these guidelines, a limited number of surgeons have performed the Ross procedure in a substantial number of adults in the United States $(18,19)$. At our center, the senior author has been performing the Ross procedure in adult patients for twentyfive-years (3). We sought to evaluate the long-term clinical and echocardiographic outcomes of these patients.

\section{Methods}

\section{Patient population}

This study was approved by our local institutional review board, and the requirement for informed consent was waived due to its retrospective nature. A single author (WHR) has performed the Ross procedure in select adult patients in Dallas, Texas, United States since 1994. The author began to mentor junior partners on the Ross procedure during select cases starting in 2001 while continuing to operate as the primary surgeon for additional cases. Adult patients (age $\geq 17$ years) with indication for SAVR were offered the Ross operation as a valve replacement choice in addition to mechanical valve replacement (20). Preoperative, operative, and immediate postoperative characteristics were ascertained from the history and physical performed during preoperative consultation, operative notes, discharge summaries from the index admission, and STS database forms maintained in the patients' charts.

\section{Operative technique}

In every case, the Ross procedure was performed as a free- standing root with all excess pulmonary artery trimmed to the pulmonary sinotubular junction (STJ), as described previously (3). When necessary to match the autograft annulus diameter, a circumferential aortic annuloplasty using 3-0 prolene was performed. Before 2017, the annular suture line consisted of 4-0 prolene interrupted sutures tied over a double layer of autologous pericardial buttress. Starting in 2017, the autograft was routinely supported by an external Dacron graft (21). When there was mismatch of the ascending aorta to the autograft or when the ascending aorta was $3.5 \mathrm{~cm}$ or greater, an interposition graft (Hemashiled Platinum Woven Double Velour Vascular Graft; MAQUET Cardiovascular LLC, Wange, NJ) was used. Early in the series, pulmonary homografts were sized by body surface area. After we identified and reported risk factors for early homograft stenosis in 2006 (4), all homografts were intentionally oversized, selected from male donors, and cryopreserved for an extended period of time. After 2011, all pulmonary homografts were also decellularized. All patients were treated with beta-blockers for at least one-year postoperatively.

\section{Echocardiographic technique}

Preoperative and early postoperative aortic stenosis (AS) and aortic insufficiency (AI) were assessed via transthoracic echocardiograms (TTE) in accordance with contemporary practice guidelines (16). Multiple views were obtained including parasternal long axis and apical 5-chamber. Continuous Doppler was used to determine deceleration slope and pressure half time of regurgitant jets. AS and AI were graded using standardized values, with severity reported as none/trace, mild, moderate, moderate-severe, or severe. All preoperative and early postoperative TTEs were reviewed by the senior surgeon (WHR). Many later postoperative TTEs were performed and initially interpreted by the patients' primary cardiologists, outside of our institution. In these cases, every effort was made to obtain the most recent available TTE images for our review or, when possible, TTE was repeated at our institution. As a last resort, echocardiography reports from the patients' cardiologist were faxed to our clinic for review.

\section{Long-term follow-up and assessment of valve performance}

The primary outcome was long-term survival. Most recent vital status was obtained via review of the patient's medical 
records. In cases where last clinical contact with the patient exceeded 1-year, patients were contacted by phone to encourage their return to clinic and to ascertain vital status and need for any Ross-related reintervention since last clinical follow-up. When we were unable to contact a patient or their emergency contact, rigorous review of publicly-available obituaries was performed according to a previously-validated methodology to attempt to identify a date of death for the patient (22). Follow-up was completed on April 1, 2021.

We evaluated long-term performance of the pulmonary autograft and homograft using previously established definitions $(23,24)$. Pulmonary autograft degeneration was defined as moderate-severe or severe valvular regurgitation on TTE ( $>2+\mathrm{AI})$. Homograft degeneration was defined as moderate-severe or severe valvular regurgitation or peak systolic valvular gradient $>40 \mathrm{mmHg}$.

\section{Statistical analysis}

Categorical variables are reported as counts and percentages. Continuous variables are presented as mean \pm standard deviation or median with interquartile range (IQR), as appropriate after assessing for normality with the Kolmogorov-Smirnov test. A Kaplan-Meier analysis was performed to evaluate survival over the long-term. Overall survival of the study cohort was compared against an ageand sex-matched general United States population using census life tables from 1994-2012, with patients undergoing Ross after 2012 matched with 2012 census data, using the R package "surexp.fr." For survival analysis, patients were followed until death (as confirmed by their medical record or obituary search) or censored at the time of last clinical contact or follow-up phone call. Patients undergoing Rossrelated reintervention were not censored at the time of reintervention during survival analyses.

Nonparametric estimates of the cumulative incidence of Ross-related intervention(s) were generated after accounting for the competing hazard of mortality (25). Patients were followed until first reintervention on the autograft or homograft (tracked individually and as a combined endpoint), death, or censored at last clinical contact or follow-up phone call. Finally, for valve performance analyses, patients were followed until the first diagnosis of valve dysfunction, death, or censored at the time of most recent TTE without evidence of valve dysfunction. Patients suffering operative mortality (within 30-days of the index procedure) were excluded from reintervention and valve-performance analyses. Kaplan-Meier survival and cumulative incidence estimates are reported as percentages with $95 \%$ confidence intervals (CI). Statistical significance was defined as $\mathrm{P}$ value $<0.05$, and statistical analysis was performed with RStudio version 1.0.143 (RStudio, Boston, Massachusetts).

\section{Results}

\section{Preoperative characteristics}

A total of 225 patients underwent the Ross procedure from 1994-2019. Baseline patient characteristics are summarized in Table 1. The patients ranged from 17 to 65 years old (mean $42 \pm 11$ years), and 62 (28\%) were at least 50 years old. The patients were predominantly male $(\mathrm{n}=157,70 \%)$ and usually had a bicuspid aortic valve $(\mathrm{n}=179$, $80 \%)$. The most common indications for surgery were AI $(\mathrm{n}=94,42 \%)$, AS $(\mathrm{n}=81,36 \%)$, and mixed etiology $(\mathrm{n}=46$, $20 \%)$. Endocarditis had been diagnosed prior to surgery in $24(11 \%)$ patients, and $6(2.7 \%)$ patients had active endocarditis and were receiving antibiotics at the time of surgery. Prior sternotomy had been performed in 17 (7.6\%) patients for aortic valvotomy $(n=5)$, coarctation repair $(n=4)$, SAVR $(n=3)$, aortic valve repair $(n=2)$, removal of subaortic membrane $(n=1)$, patent ductus arteriosus closure $(n=1)$, and coronary artery bypass grafting $(\mathrm{CABG} ; \mathrm{n}=1)$.

\section{Procedural details and early postoperative outcomes}

Median cardiopulmonary bypass and aortic cross-clamp times were 204 (IQR: 175-213) and 168 (IQR: 151-183) minutes, respectively. Aortic annuloplasty was performed in $60(27 \%)$ cases. Concomitant procedures were performed in $55(27 \%)$ cases (Table 1).

In-hospital mortality occurred in two $(0.9 \%)$ patients and 30 -day mortality in five $(2.2 \%)$ patients, including the two patients who died prior to discharge. The cause of mortality was unique in each case. Prior to discharge, one patient developed heparin-induced thrombocytopenia, and another had unrecoverable right-ventricular failure. After discharge but within 30 days, one patient each died of myocardial infarction, pulmonary embolism, and recurrent endocarditis (Table 2). A total of 29 (13\%) patients suffered at least one non-fatal postoperative complication, which included (non-mutually-exclusive): reoperation for bleeding $(\mathrm{n}=7,3.1 \%)$, heart block requiring pacemaker placement $(\mathrm{n}=9,4.0 \%)$, pleural effusion requiring thoracentesis $(\mathrm{n}=5$, 


\begin{tabular}{ll}
$\begin{array}{l}\text { Table } 1 \text { Preoperative and operative characteristics of adult patients } \\
\text { undergoing the Ross procedure }\end{array}$ & Value \\
\hline Characteristic & $42 \pm 11$ \\
\hline Age, years & $157[70]$ \\
Male & $72[32]$ \\
Hypertension & $12(5.2)$ \\
Coronary artery disease & $98[44]$ \\
NHYA Class III or IV & $15(6.7)$ \\
Diabetes & $8(3.6)$ \\
Chronic kidney disease & $56[25]$ \\
Obese (BMI >30 kg/m ${ }^{2}$ ) & \\
Smoker & $42[19]$ \\
Active & $40[18]$ \\
Former & $57 \pm 9$ \\
Left ventricular ejection fraction, \% & $2(0.9)$ \\
Aortic Leaflets & $179[80]$ \\
Unicuspid & $36[16]$ \\
Bicuspid & $10.4)$ \\
Tricuspid & \\
Quadricuspid & \\
Prosthetic valve & \\
Unknown & \\
Dominant Aortic Valve Lesion
\end{tabular}

\section{Dominant Aortic Valve Lesion}

$\begin{array}{ll}\text { Aortic insufficiency } & 94[42] \\ \text { Aortic stenosis } & 81[36] \\ \text { Mixed } & 46[20] \\ \text { Other } & 4[2]\end{array}$

$\begin{array}{ll}\text { Endocarditis } & \\ \text { Treated } & 18(8.0) \\ \text { Active } & 6(2.7) \\ \text { Aortic annuloplasty } & 60[27] \\ \text { Concomitant procedures } & \\ \text { Ascending aorta replacement } & 40[18] \\ \text { Aortoplasty } & 5(2.4) \\ \text { CABG (planned) } & 2(0.9) \\ \text { CABG (unplanned) } & 10(4.4) \\ \text { Mitral valve repair } & 4(1.9) \\ \text { Tricuspid valve annuloplasty } & 1(0.9) \\ \text { Ventricular septal defect repair } & 3(1.5)\end{array}$

Table 1 (continued)

\begin{tabular}{ll} 
Table 1 (continued) & \\
\hline Characteristic & Value \\
\hline Cardiopulmonary bypass time, min & $204[175-213]$ \\
\hline Aortic cross-clamp time, min & 168 [151-183] \\
\hline $\begin{array}{l}\text { Data presented as N (\%), mean } \pm \text { standard deviation, or median } \\
\text { [interquartile range]. }\end{array}$
\end{tabular}

Table 2 Primary cause of mortality in patients undergoing the Ross procedure

\begin{tabular}{ll}
\hline Cause of death & Count \\
\hline Ross-related (all) & 8 \\
Ross-related (within 30 days) & 5 \\
Myocardial infarction & 1 \\
Pulmonary embolism & 1 \\
\hline Recurrent endocarditis (autograft) & 1 \\
\hline Heparin-induced thrombocytopenia & 1 \\
\hline Right ventricular failure & 1 \\
Ross-related (late) & 3 \\
\hline Death after reoperation & 1 \\
\hline Endocarditis (homograft) & 2 \\
\hline Non-Ross-related & 16 \\
\hline Cancer & 8 \\
Cardiomyopathy & 3 \\
Cirrhosis & 1 \\
End-stage renal disease & 1 \\
\hline Pneumonia & 1 \\
Sepsis (urinary tract infection) & 1 \\
\hline Trauma & 1 \\
\hline Unknown & 1 \\
\hline
\end{tabular}

$2.2 \%)$ or readmission for medical management $(\mathrm{n}=2,0.9 \%)$, prolonged intubation requiring tracheostomy $(\mathrm{n}=2,0.9 \%)$, pneumonia $(\mathrm{n}=1,0.4 \%)$, empyema requiring thoracotomy $(\mathrm{n}=1,0.5 \%)$, bowel ischemia requiring partial colectomy $(n=1,0.5 \%)$, endocarditis $(n=1,0.5 \%)$, pneumothorax requiring chest tube placement $(\mathrm{n}=1,0.5 \%)$, and renal failure with new requirement for dialysis $(n=1,0.5 \%)$. There were no cases of early autograft or homograft failure 


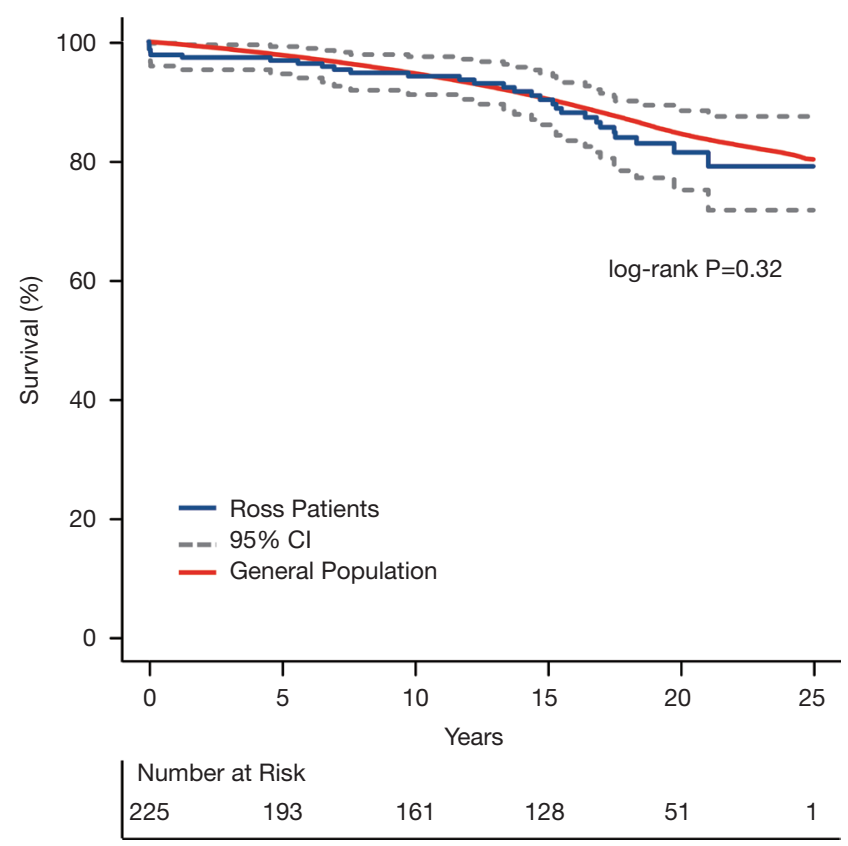

Figure 1 Kaplan-Meier survival curves of patients undergoing the Ross procedure (blue, with 95\% confidence intervals in grey) and the age- and sex-matched United States general population (red).

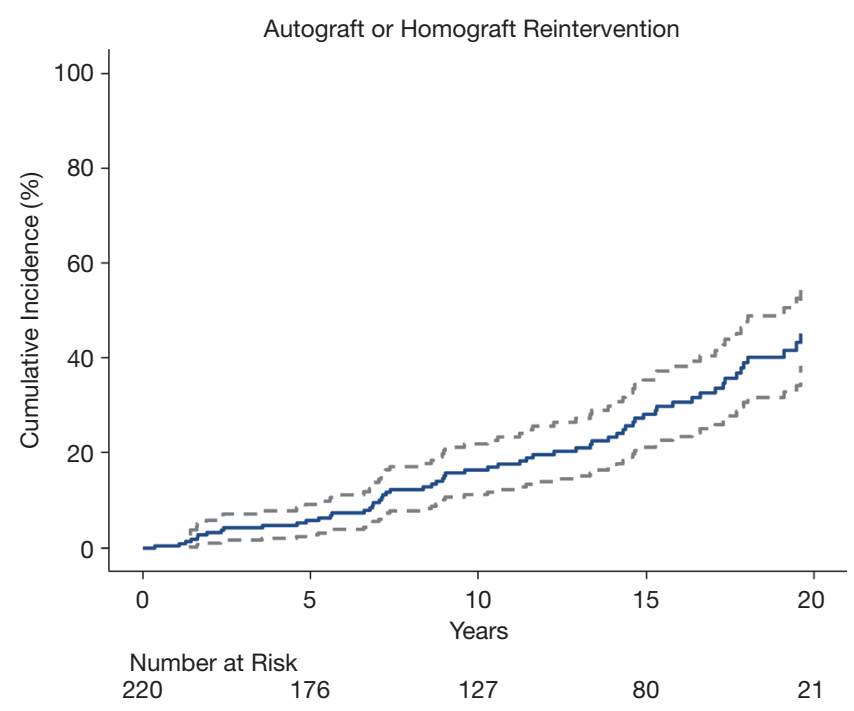

Figure 2 Cumulative incidence of autograft or homograft reintervention following the Ross procedure (blue line with $95 \%$ confidence intervals), after accounting for mortality as a competing risk.

requiring reoperation during the index admission. After 30 days, there were no further mortalities within 1-year of the Ross procedure.

\section{Long-term survival}

Median follow-up was 17 (IQR: 12-20) years, and maximum follow-up was 25 years. At the minimum, patient vital status within 2 years of conclusion of follow-up was confirmed for $90 \%$ of patients. Long-term survival of patients undergoing the Ross procedure approximated an age- and sex-matched general population (log-rank $\mathrm{P}=0.32$, Figure 1). Estimates of freedom from all-cause mortality (with 95\% CI) at 1-, 10 - and 20-year were 97.8\% (95.9-99.7\%), 94.2\% (91.0$97.4 \%)$, and $81.3 \%(74.8-88.3 \%)$, respectively. There were 24 late mortalities, after a median of 15 [9-17] years (Table 2). Three late deaths were from Ross-related causes: one from complications following redo SAVR performed outside our institution and two from endocarditis of the homograft.

\section{Ross-related reintervention and long-term valve performance}

Patients suffering mortality within 30 days of the Ross procedure were excluded from reintervention and valve performance analyses. Of the remaining 220 patients, 64 patients $(28 \%)$ underwent 70 total reinterventions: $40(18 \%)$ patients underwent reoperations on the pulmonary autograft alone, $8(3.6 \%)$ on their pulmonary homograft alone, and $16(7.2 \%)$ on both the autograft and homograft. Of the 16 patients undergoing reintervention on both valves, 10 patients underwent combined reinterventions and 6 patients underwent separate reinterventions that occurred a median of 10 (IQR: 6-11) years apart. Postoperative mortality occurred after one (1.4\%) reoperation, which was performed on the pulmonary autograft outside of our institution. The estimated cumulative incidence (with $95 \%$ CI) of any valve reintervention at 10-, 15-, and 20-year was $16 \%$ (12-20\%), 28\% (21-35\%), and 45\% (36-54\%), respectively (Figure 2 ).

Reintervention on the pulmonary autograft occurred a median of 12 years (IQR: 7-15 years) after the Ross procedure in 56 patients (1.7\% per patient-year). Indications for reintervention included autograft dilation with aortic insufficiency $(n=33,59 \%)$ isolated aortic insufficiency $(n=18,32 \%)$, endocarditis $(n=4,7.1 \%)$, and ruptured leaflet after a traumatic fall from height $(\mathrm{n}=1,1.8 \%)$. An autograft valve-sparing aortic root replacement (with or without ascending aorta replacement) was performed in $16(29 \%)$ patients, whereas the remainder underwent composite valve and root replacement $(n=26,46 \%)$, isolated aortic valve replacement without root replacement $(n=12$, 


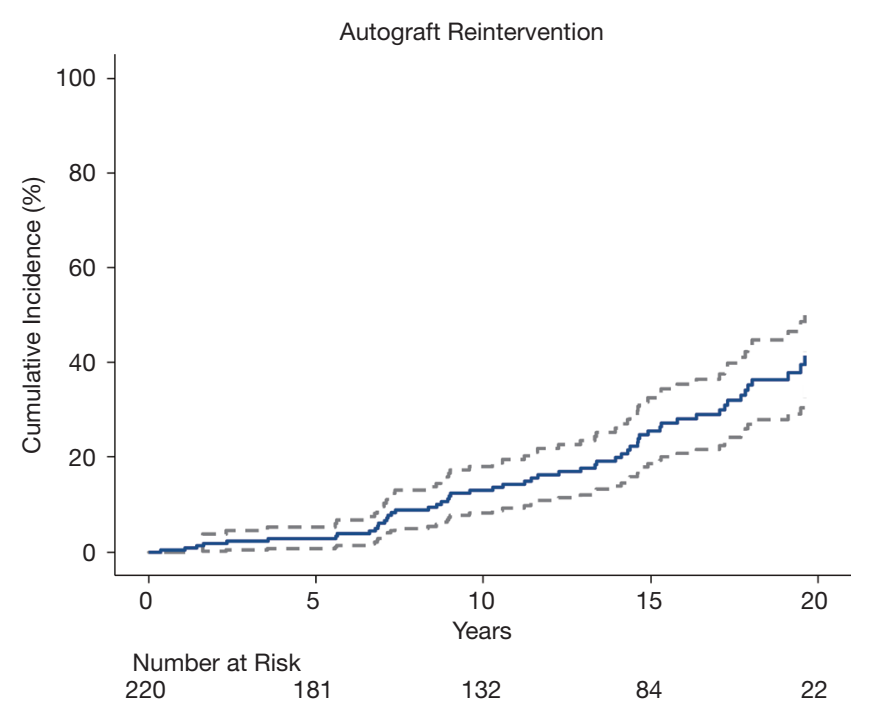

Figure 3 Cumulative incidence of autograft reintervention following the Ross procedure (blue line with 95\% confidence intervals), after accounting for mortality as a competing risk.

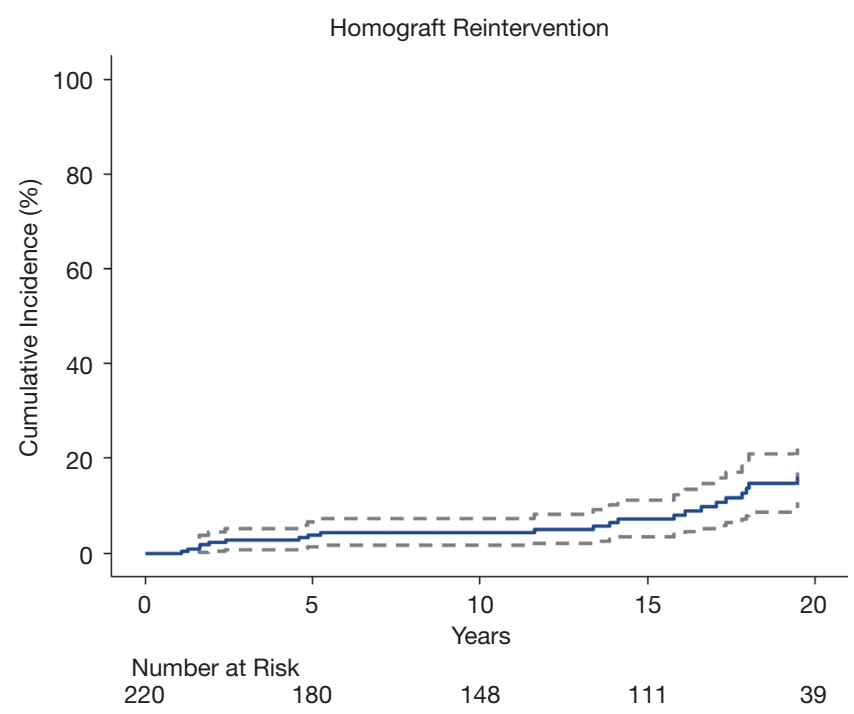

Figure 4 Cumulative incidence of homograft reintervention following the Ross procedure (blue line with 95\% confidence intervals), after accounting for mortality as a competing risk.

$21 \%)$, transcatheter aortic valve replacement ( $\mathrm{n}=1,1.8 \%)$, or repair of a pseudoaneurysm at the suture line of the autograft and ascending aorta $(\mathrm{n}=1,1.8 \%)$. Accounting for death as a competing risk, the estimated cumulative incidence (with 95\% CI) of autograft reintervention at 10-,
$15-$, and 20 -year was $13 \%(10-16 \%), 26 \%(21-31 \%)$, and $41 \%$ (35-47\%), respectively (Figure 3). At the conclusion of follow-up, 5 patients had moderate-to-severe AI on their most recent TTE and were under regular, close surveillance of their valve function without immediate plans for reintervention, and 1 patient with severe AI was scheduled for reintervention. The estimated cumulative incidence (with $95 \% \mathrm{CI}$ ) of autograft dysfunction, including cases not undergoing reintervention, at 10-, 15-, and 20-year was $16 \%(12-20 \%), 29 \%(24-34 \%)$, and $52 \%(45-59 \%)$, respectively.

Reintervention on the pulmonary homograft occurred a median of 14 years (IQR: 4-17 years) after the Ross procedure in 24 patients $(0.7 \%$ per patient-year). Indications for reintervention included isolated homograft stenosis $(\mathrm{n}=17,71 \%)$, combined homograft stenosis and insufficiency $(n=3,13 \%)$, endocarditis $(n=3,13 \%)$, and unintentional homograft injury during redo sternotomy for CABG ( $\mathrm{n}=1,4.2 \%)$. Reinterventions included surgical pulmonic valve replacement $(\mathrm{n}=17,71 \%)$, transcatheter pulmonic valve replacement $(\mathrm{n}=4,17 \%)$, and transcatheter balloon valvuloplasty $(n=3,13 \%)$. Accounting for death as a competing risk, the estimated cumulative incidence (with 95\% CI) of homograft reintervention at 10-, 15-, and 20 -years was $4.2 \%(3.2-5.2 \%), 7.7 \%(5.2-10 \%)$, and $16 \%$ (11-21\%), respectively (Figure 4). The estimated cumulative incidence (with 95\% CI) of homograft dysfunction at 10-, $15-$, and 20 -year was $6.2 \%$ (4.2-7.2\%), 8.6\% (6.4-11\%), and $16 \%(11-21 \%)$, respectively.

\section{Discussion}

In this report, we have retrospectively analyzed the clinical and echocardiographic outcomes of 225 consecutive adult patients undergoing the Ross procedure. Our primary findings were the following: (I) long-term survival following the Ross procedure was non-inferior to an age- and sexmatched general population; (II) the need for reintervention increased steadily during the second decade following the Ross procedure, though less than half of patients require a reintervention before 20 years, and (III) reintervention can be performed safely, even in cases requiring redo sternotomy.

Several other centers have reported similar long-term outcomes following the Ross procedure in adults (7-12, 18,19). In particular, recent multicenter registry studies have reported on two of the largest cohorts of patients 
undergoing the Ross procedure to date. Romeo and colleagues reported on outcomes of 1,431 adult patients undergoing the Ross procedure in Australia, Belgium, Brazil, Canada, or Germany (13). Median follow-up was 9.2 years, with similar rates of in-hospital mortality and long-term survival as reported in our series. Aboud and colleagues reported on 2,444 adult patients undergoing the Ross procedure primarily in Germany (14). Median followup was again 9.2 years, and long-term survival was noninferior to an age- and sex-matched general population.

Although survival outcomes (as well as rates of homograft reintervention) in these two reports were similar to what we have reported among our patients, rate of autograft reintervention was higher in our series. This may be explained by several factors such as difference in technique, or the greater duration of follow-up in our study. We are also confident in our ability to provide a safe reintervention, which may allow us to be relatively more aggressive towards reintervention in autografts beginning to show signs of deterioration. As with other prior reports, perioperative mortality during reintervention was low, and in fact was $0 \%$ when the reoperation was performed at our center $(4,26,27)$. However, this difference is most likely predominantly driven by patient selection. Whereas our cohort included $43 \%$ of patients with predominant AI (in which we aggressively used aortic annuloplasty), only $22 \%$ of the Aboud cohort had predominant AI, and $10 \%$ of the Romeo cohort had severe AI. Severe or predominant preoperative AI has been consistently shown to increase the risk for autograft reintervention $(12,13,14,28)$. Indeed, we also previously reported that $\mathrm{AI}$ increases the risk for autograft reintervention (3) and thereafter adjusted our selection criteria. In patients with predominant AI, we no longer perform the Ross procedure if we deem the valve repairable, when $\mathrm{AI}$ is related to a connective tissue disorder, or when the aortic annulus is massively dilated $(\geq 32 \mathrm{~mm})$. Since our report in 2011, less than $10 \%$ of patients undergoing the Ross procedure at our center had predominant AI preoperatively. Additional follow-up is necessary to determine whether this change in selection criteria will ultimately reduce our reported reoperation rates because these patients are just starting to enter the second decade of follow-up. We also expect that our transition to a fullysupported autograft technique in 2017 may be effective in reducing reintervention in patients with predominant $\mathrm{AI}$, but long-term follow-up of these patients will be necessary to confirm this hypothesis.
This report is subject to several limitations, including those inherent to any retrospective analysis. Achieving maximally thorough clinical and echocardiographic followup of patients undergoing surgery over a span of 25 years was challenging. Some bias may have been introduced by censoring patients lost to follow-up; however our completeness of follow-up is consistent with many other reports from prospectively maintained registries and/or countries with healthcare systems that facilitate patient follow-up to a greater degree than the currently fragmented system in the United States $(7,12,14)$. This series of patients underwent surgery during a time span when bicuspid aortic valve reimplantation was not fully adopted at our center, so many patients with predominant AI were offered a Ross procedure with concomitant aortic annuloplasty. More recently, we have favored valve repair and reimplantation, when possible, in patients with predominant AI. Finally, this series of cases was performed or directly mentored by a single surgeon with extensive experience performing the Ross procedure, and the outcomes may not be generalizable to centers and surgeons with less experience performing the Ross procedure.

These outcomes may also be positively biased as a result of careful patient selection, and future reports would ideally include a comparator group. To date, only one randomized trial, performed at a single center, has included an arm of patients undergoing the Ross procedure (29). Even nonrandomized, matched comparison studies are limited in number and scope (30-32). We concur with a recent editorial that suggested that additional randomized studies to definitively evaluate the Ross procedure against other surgical options in the young- and middle-aged adult population are warranted (33). However, given the limited number of surgeons currently performing the Ross procedure and the substantial length of follow-up that would be required to potentially demonstrate any clinicallysignificant advantage over more conventional strategies, completion of a randomized trial may not be practical. Perhaps our results, which supplement the current evidence basis, may at least motivate a select group of surgeons to pursue dedicated training and mentoring in the Ross procedure, particularly in the United States where so few centers perform this surgery in adult patients $(34,35)$.

In conclusion, our experience performing the Ross procedure in adult patients over the last 25 years has demonstrated the ability of this technique to restore normal life-expectancy to young adults with critical aortic 
valve disease. This benefit has not been demonstrated for conventional SAVR. Patients should be counseled that in order to achieve the full benefits of the Ross procedure, reintervention may eventually be necessary, but the pulmonary autograft nevertheless facilitates optimized physiology and normal survival. Future work on the Ross procedure should be three-fold. Firstly, follow-up of an even greater duration is necessary to understand what will happen to the roughly $50 \%$ of autografts that are still functioning properly into the third decade following the index procedure-is reoperation inevitable if the patient survives long enough or does the incidence of reintervention eventually plateau? How the increasing availability of TAVR for patients with degenerated autografts impacts the risks and outcomes of reintervention will also become clearer with additional follow-up. Secondly, research should be targeted towards further improving both surgical technique and patient selection with goals of reducing the incidence of reintervention and/or lengthening the time to reintervention after the Ross procedure. Thirdly, and perhaps most critically, our results, along with the outcomes of several other high-volume centers, support the need to make available dedicated training for the next generation of Ross surgeons in order to ensure that this procedure will continue to be available to young and middle-aged adults who prefer to avoid conventional valve replacement. Perhaps if additional surgeons with dedicated Ross training demonstrate acceptable long-term outcomes, the STS guidelines may be modified as well.

\section{Acknowledgments}

Funding: None.

\section{Footnote}

Conflicts of Interest: JJS effort was supported by a philanthropic gift from Satish and Yasmin Gupta. The other authors have no conflicts of interest to declare.

Open Access Statement: This is an Open Access article distributed in accordance with the Creative Commons Attribution-NonCommercial-NoDerivs 4.0 International License (CC BY-NC-ND 4.0), which permits the noncommercial replication and distribution of the article with the strict proviso that no changes or edits are made and the original work is properly cited (including links to both the formal publication through the relevant DOI and the license). See: https://creativecommons.org/licenses/by-nc-nd/4.0/.

\section{References}

1. Glaser N, Persson M, Jackson V, et al. Loss in Life Expectancy After Surgical Aortic Valve Replacement: SWEDEHEART Study. J Am Coll Cardiol 2019;74:26-33.

2. Ross DN. Replacement of aortic and mitral valves with a pulmonary autograft. Lancet 1967;2:956-8.

3. Ryan WH, Prince SL, Culica D, et al. The Ross procedure performed for aortic insufficiency is associated with increased autograft reoperation. Ann Thorac Surg 2011;91:64-9; discussion 69-70.

4. Brinkman WT, Herbert MA, Prince SL, et al. Redo autograft operations after the Ross procedure. Ann Thorac Surg 2012;93:1477-81; discussion 1481-22.

5. Ryan WH, Herbert MA, Dewey TM, et al. The occurrence of postoperative pulmonary homograft stenosis in adult patients undergoing the Ross procedure. J Heart Valve Dis 2006;15:108-13; discussion 113-4.

6. Mazine A, El-Hamamsy I, Verma S, et al. Ross Procedure in Adults for Cardiologists and Cardiac Surgeons: JACC State-of-the-Art Review. J Am Coll Cardiol 2018;72:2761-77.

7. Skillington PD, Mokhles MM, Takkenberg JJ, et al. The Ross procedure using autologous support of the pulmonary autograft: techniques and late results. J Thorac Cardiovasc Surg 2015;149:S46-52.

8. Andreas $M$, Seebacher $G$, Reida E, et al. A single-center experience with the ross procedure over 20 years. Ann Thorac Surg 2014;97:182-8.

9. Sievers HH, Stierle U, Charitos EI, et al. A multicentre evaluation of the autograft procedure for young patients undergoing aortic valve replacement: update on the German Ross Registry†. Eur J Cardiothorac Surg 2016;49:212-8.

10. Martin E, Mohammadi S, Jacques F, et al. Clinical Outcomes Following the Ross Procedure in Adults: A 25-Year Longitudinal Study. J Am Coll Cardiol 2017;70:1890-9.

11. Bouhout I, Ghoneim A, Poirier N, et al. Impact of the Learning Curve on Early Outcomes Following the Ross Procedure. Can J Cardiol 2017;33:493-500.

12. David TE, Ouzounian M, David CM, et al. Late results of the Ross procedure. J Thorac Cardiovasc Surg 2019;157:201-8. 
13. Romeo JLR, Papageorgiou G, da Costa FFD, et al. Longterm Clinical and Echocardiographic Outcomes in Young and Middle-aged Adults Undergoing the Ross Procedure. JAMA Cardiol 2021;6:539-48.

14. Aboud A, Charitos EI, Fujita B, et al. Long-Term Outcomes of Patients Undergoing the Ross Procedure. J Am Coll Cardiol 2021;77:1412-22.

15. Reece TB, Welke KF, O'Brien S, et al. Rethinking the ross procedure in adults. Ann Thorac Surg 2014;97:175-81.

16. Otto CM, Nishimura RA, Bonow RO, et al. 2020 ACC/ AHA Guideline for the Management of Patients With Valvular Heart Disease: A Report of the American College of Cardiology/American Heart Association Joint Committee on Clinical Practice Guidelines. Circulation 2021;143:e72-e227.

17. Svensson LG, Adams DH, Bonow RO, et al. Aortic valve and ascending aorta guidelines for management and quality measures. Ann Thorac Surg 2013;95:S1-66.

18. Starnes VA, Elsayed RS, Cohen RG, et al. Longterm outcomes with the pulmonary autograft inclusion technique in adults with bicuspid aortic valves undergoing the Ross procedure. J Thorac Cardiovasc Surg 2021. [Epub ahead of print]. doi: 10.1016/j.jtcvs.2021.01.101.

19. Elkins RC, Thompson DM, Lane MM, et al. Ross operation: 16-year experience. J Thorac Cardiovasc Surg 2008;136:623-30, 630.e1-5.

20. Capps SB, Elkins RC, Fronk DM. Body surface area as a predictor of aortic and pulmonary valve diameter. J Thorac Cardiovasc Surg 2000;119:975-82.

21. Basmadjian L, Basmadjian AJ, Stevens LM, et al. Early results of extra-aortic annuloplasty ring implantation on aortic annular dimensions. J Thorac Cardiovasc Surg 2016;151:1280-5.e1.

22. Wooley J, Neatherlin H, Mahoney C, et al. Description of a Method to Obtain Complete One-Year Follow-Up in the Society of Thoracic Surgeons/American College of Cardiology Transcatheter Valve Therapy Registry. Am J Cardiol 2018;121:758-61.

23. Akins CW, Miller DC, Turina MI, et al. Guidelines for reporting mortality and morbidity after cardiac valve interventions. Ann Thorac Surg 2008;85:1490-5.

24. Zoghbi WA, Chambers JB, Dumesnil JG, et al. Recommendations for evaluation of prosthetic valves with echocardiography and doppler ultrasound: a report From the American Society of Echocardiography's Guidelines and Standards Committee and the Task
Force on Prosthetic Valves, developed in conjunction with the American College of Cardiology Cardiovascular Imaging Committee, Cardiac Imaging Committee of the American Heart Association, the European Association of Echocardiography, a registered branch of the European Society of Cardiology, the Japanese Society of Echocardiography and the Canadian Society of Echocardiography, endorsed by the American College of Cardiology Foundation, American Heart Association, European Association of Echocardiography, a registered branch of the European Society of Cardiology, the Japanese Society of Echocardiography, and Canadian Society of Echocardiography. J Am Soc Echocardiogr 2009;22:975-1014; quiz 1082-4.

25. Scrucca L, Santucci A, Aversa F. Competing risk analysis using R: an easy guide for clinicians. Bone Marrow Transplant 2007;40:381-7.

26. Luciani GB, Lucchese G, De Rita F, et al. Reparative surgery of the pulmonary autograft: experience with Ross reoperations. Eur J Cardiothorac Surg 2012;41:1309-14; discussion 1314-5.

27. Charitos EI, Takkenberg JJ, Hanke T, et al. Reoperations on the pulmonary autograft and pulmonary homograft after the Ross procedure: An update on the German Dutch Ross Registry. J Thorac Cardiovasc Surg 2012;144:813-21; discussion 821-3.

28. Mokhles MM, Rizopoulos D, Andrinopoulou ER, et al. Autograft and pulmonary allograft performance in the second post-operative decade after the Ross procedure: insights from the Rotterdam Prospective Cohort Study. Eur Heart J 2012;33:2213-24.

29. El-Hamamsy I, Eryigit Z, Stevens LM, et al. Longterm outcomes after autograft versus homograft aortic root replacement in adults with aortic valve disease: a randomised controlled trial. Lancet 2010;376:524-31.

30. Mazine A, David TE, Rao V, et al. Long-Term Outcomes of the Ross Procedure Versus Mechanical Aortic Valve Replacement: Propensity-Matched Cohort Study. Circulation 2016;134:576-85.

31. Mokhles MM, Körtke H, Stierle U, et al. Survival comparison of the Ross procedure and mechanical valve replacement with optimal self-management anticoagulation therapy: propensity-matched cohort study. Circulation 2011;123:31-8.

32. Buratto E, Shi WY, Wynne R, et al. Improved Survival After the Ross Procedure Compared With Mechanical 
Aortic Valve Replacement. J Am Coll Cardiol 2018;71:1337-44.

33. Bonow RO, O'Gara PT. Reconsidering the Ross Procedure. JAMA Cardiol 2021;6:548.

34. Pettersson GB, Blackstone EH. Is it Time to Reconsider

Cite this article as: Ryan $\mathrm{WH}$, Squiers JJ, Harrington KB, Goodenow T, Rawitscher C, Schaffer JM, DiMaio JM, Brinkman WT. Long-term outcomes of the Ross procedure in adults. Ann Cardiothorac Surg 2021;10(4):499-508. doi: 10.21037/acs-2021-rp-fs-28
Use of the Ross Procedure for Adults? J Am Coll Cardiol 2018;71:1345-6.

35. Bonow RO. Resurgence of the Ross procedure. Ann Cardiothorac Surg 2021; in press. 